\title{
Squamous metaplasia within a sigmoid adenoma. A rare feature
}

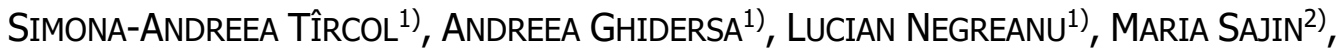 \\ ADRIAN VASILE DUMITRU2) \\ 1) II ${ }^{\text {md }}$ Department of Internal Medicine - Gastroenterology, Bucharest Emergency University Hospital, Romania \\ 2) Department of Pathology, Bucharest Emergency University Hospital, Romania
}

\begin{abstract}
Squamous metaplasia occurring within a colorectal polyp is a rare finding, having a reported incidence of approximately $0.44 \%$. The origin of the squamous cells in this type of setting is uncertain (mechanical irritation and chronic inflammation are potential predisposing factors). It has been implied that the significance of squamous metaplasia in colorectal adenomas is that of a preneoplastic lesion for squamous cell and adenosquamous carcinoma, however the evidence to support this statement is scarce. We present a case of a large tubulovillous adenoma located in the sigmoid, with low-grade dysplasia and multiple foci of p16-positive immunoexpression squamous metaplasia in a 54-year-old Caucasian male, presenting with rectal bleeding.
\end{abstract}

Keywords: squamous metaplasia, sigmoid adenoma, dyskeratocytes, p16-positive, chromoendoscopy, SFI.

\section{ㅁ Introduction}

Metaplasia is defined as a reversible adaptive transformation in which another cell type that is better equipped to endure the unfriendly environment replaces one differentiated subset of cells. Squamous metaplasia is the most frequent type of epithelial metaplasia. Although it is a purely benign process, under persistent predisposing influences the metaplastic epithelium may undergo a malignant transformation [1].

The occurrence of squamous metaplasia within a colorectal polyp is extremely uncommon. In a large study of 5778 colorectal adenomas conducted by Bansal et al., the incidence was reported to be of approximately $0.44 \%$ [1]. A similar review targeting 750 patients with colorectal adenomas identified three cases (representing $0.4 \%$ ) of squamous differentiation [2]. The average age of the patients was 61 years (range, 39-80 years), with a predominance of the male gender $(76 \%)$. Concerning the location, the adenomas were found along the entire length of the colon, with a tubular, villous or tubulovillous histological pattern. The squamous cells appeared to be organized into discrete nests, found equally within the surface, middle and/or base of the adenomas. As for the immunoprofile of these cells, the ones tested were reactive to keratin [1].

The origin of these squamous cells in the current setting is uncertain. Potential predisposing factors could be mechanical irritation and chronic inflammation $[3,4]$. As for the significance of this form of metaplasia in colorectal adenomas, it has been implied that these cells may represent precursor lesions for squamous neoplasms in the colon (squamous cell and adenosquamous carcinoma) [5-7], as in a few of these cases the metaplastic cells were found in areas of intramucosal adenocarcinoma [1, $8-12]$.
P16 is a tumor suppressor gene with function in cell cycle regulation. The abnormal function of this gene is thought to be among the earliest events involved in the progression of carcinogenesis [13-17].

Since 1979, there have been approximately 33 reports of colorectal adenomas with squamous metaplasia documented in the literature [11].

\section{Aim}

We present an additional such case, involving a tubulovillous adenoma of the sigmoid with low-grade dysplasia, multiple foci of squamous metaplasia and p16 immunoexpression in a 54-year-old Caucasian male, presenting with rectal bleeding.

\section{ㅁ Case presentation}

\section{Clinical data}

A 54-year-old overweight Caucasian male, with a history of hypertension and hyperlipidemia, presented in our Clinic with rectal bleeding. He did not have any other significant symptoms. Bleeding started one week before presentation. His medical comorbidities included obesity, hypertension and dyslipidemia. He was an occasional smoker and he did not have a screening colonoscopy. The physical examination was unremarkable, except for the digital rectal examination, which revealed the presence of bright red blood in the rectum.

\section{Laboratory examination}

Complete blood count showed that white blood cell count was $6180 / \mathrm{mm}^{3}$ [normal range (NR): $4000-10000 / \mathrm{mm}^{3}$ ], hemoglobin level $13.4 \mathrm{~g} / \mathrm{dL}$ (NR: 12.9-15.9 g/dL), and platelet count $228600 / \mathrm{mm}^{3}$ (NR: $155000-366000 / \mathrm{mm}^{3}$ ). Blood chemistry analysis showed that triglyceride level was

This is an open-access article distributed under the terms of a Creative Commons Attribution-NonCommercial-ShareAlike 4.0 International Public License, which permits unrestricted use, adaptation, distribution and reproduction in any medium, non-commercially, provided the new creations are licensed under identical terms as the original work and the original work is properly cited. 
$311 \mathrm{mg} / \mathrm{dL}$ (NR: 30-150 mg/dL), blood urea nitrogen $63 \mathrm{mg} / \mathrm{dL}$ (NR: $12-45 \mathrm{mg} / \mathrm{dL}$ ), creatinine $1.23 \mathrm{mg} / \mathrm{dL}$ (NR: $0.5-1.5 \mathrm{mg} / \mathrm{dL}$ ), glucose $180 \mathrm{mg} / \mathrm{dL}$ (NR: $74-106 \mathrm{mg} / \mathrm{dL}$ ), glycated hemoglobin level $8.8 \%$, alanine aminotransferase $36 \mathrm{U} / \mathrm{L}$ (NR: 3-65 U/L) and aspartate aminotransferase $17 \mathrm{U} / \mathrm{L}$ (NR: 2-40 U/L).

\section{Imaging and histopathology}

Colonoscopy was performed with the detection and removal of two sessile polyps measuring $2 \mathrm{~mm}$ and $3 \mathrm{~mm}$ in diameter, located in the transverse and descending colon, respectively. The histopathological (HP) examination revealed diffuse moderate dysplasia of the adenomatous structures.

The lesion responsible for the bleeding was a voluminous pedunculated polyp $(2.5 / 1.5 / 1.5 \mathrm{~cm}$, a pedicle of $0.8 \mathrm{~cm}$ diameter), with hemorrhagic regions, located in the sigmoid (Figure 1). Examination using digital chromoendoscopy with variable intelligent staining technology (VIST) and spectral focused imaging (SFI) mode analyzing surface and pit pattern was suggestive for a tubulovillous adenoma (irregular surface, tubular and villous areas).

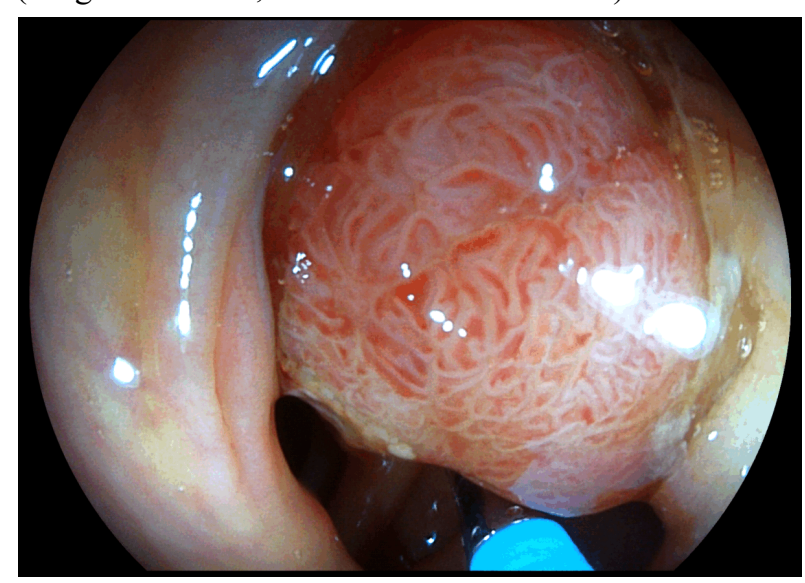

Figure 1 - Intraprocedural image of a voluminous pedunculated polyp, with irregular surface tubulovillous appearance; SFI mode. SFI: Spectral focused imaging.

Snare polypectomy was performed after injecting Epinephrine solution (1:10 000) and a hemostatic clip was applied at the place of resection. After the colonoscopic

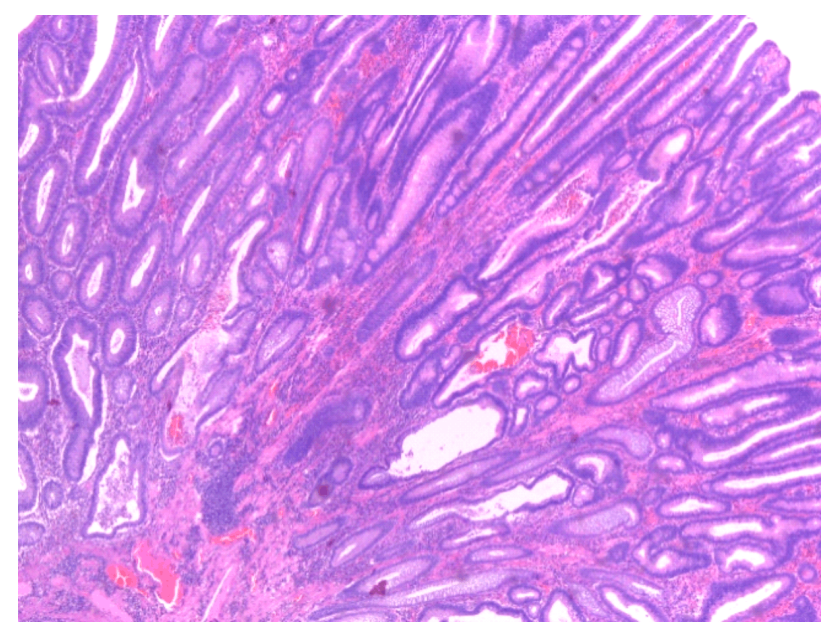

Figure 2 - Colonic adenoma with low-grade dysplasia. HE staining, $\times 40$. removal of the tumor, the tissue fragments were sent for processing and examination to our Department of Pathology. Tissue samples were fixed with $10 \%$ neutral buffered formalin and sent for the HP processing by conventional method using paraffin inclusion and Hematoxylin-Eosin (HE) staining. Also, immunohistochemical (IHC) tests were performed. The paraffin blocks acquired by HP processing were sectioned at microtome resulting 3- $\mu \mathrm{m}-$ thickness sections mounted on slides covered with polyL-lysine. After that, the sections were deparaffinized in toluene and alcohol successive baths, one hour, 15 minutes by bath and rehydrated (three successive alcohol baths with decreased concentration: $96 \%, 80 \%$ and $70 \%, 10$ minutes in each bath, followed by a bath with distilled water, were the sections were held for 10 minutes). These steps were followed by washing in phosphate-buffered saline (PBS), incubation with normal serum, for 20 minutes, incubation with primary antibody overnight, Dako Labeled Streptavidin-Biotin (LSAB) kit, washing in carbonate buffer and development in 3,3'-Diaminobenzidine (DAB) hydrochloride/hydrogen peroxide and nuclear counterstaining with Mayer's Hematoxylin. We used the following antibodies from NeoMarkers LabVision: cytokeratin 20 (CK20), $\beta$-catenin, caudal-type homeobox 2 (CDX2), p16 and $\mathrm{Ki} 67$.

Histologically, the excised fragment was identified as a tubulovillous adenoma with low-grade dysplasia, comprising multiple foci of complete and incomplete squamous metaplasia, similar to squamous morules commonly found in some endometrial carcinomas, as it can be seen in Figures 2-7. IHC staining was positive for p16 within the squamous nests and in few glandular cells. $\beta$-Catenin was positive within the areas of squamous metaplasia, but CK20 appeared negative. CDX2 had a strong nuclear expression in the glandular epithelium, while appearing faintly positive in the squamous foci. Ki67 was negative in the areas of squamous metaplasia, suggesting that those areas are mitotically inactive (Figures 8 and 9).

Upper gastrointestinal endoscopy was performed and revealed no mucosal abnormalities, as well as a negative result for the Helicobacter pylori test.

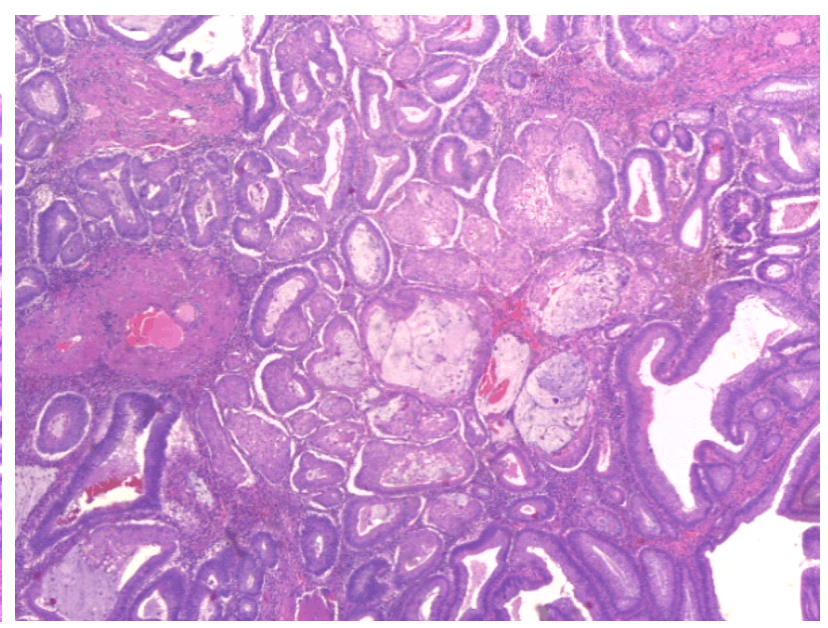

Figure 3 - Extensive complete and incomplete squamous metaplasia in a colonic adenoma. HE staining, $\times 100$. 


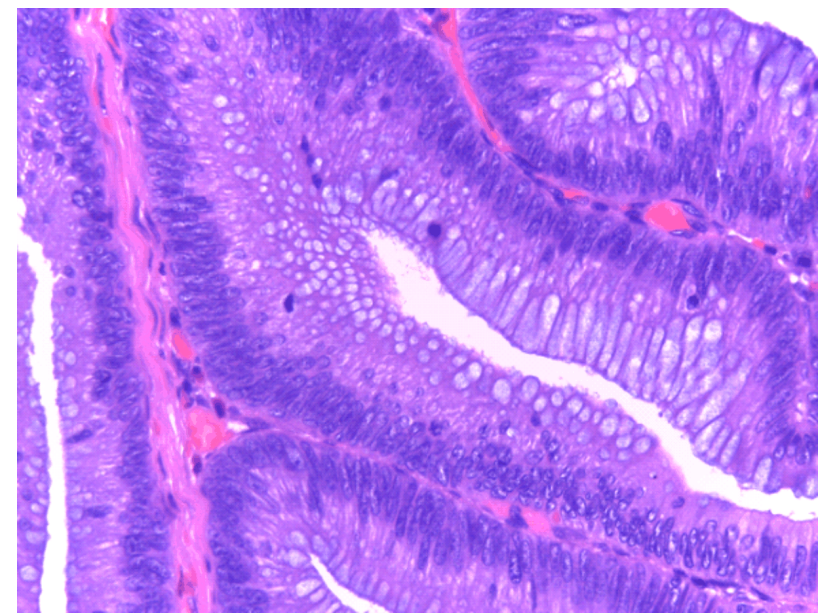

Figure 4 - Colonic adenoma. Dysplastic epithelium comprised of hyperchromatic, elongated nuclei arranged in a pseudostratified manner. Note the high mitotic count and the focal loss of polarity. HE staining, $\times 200$.

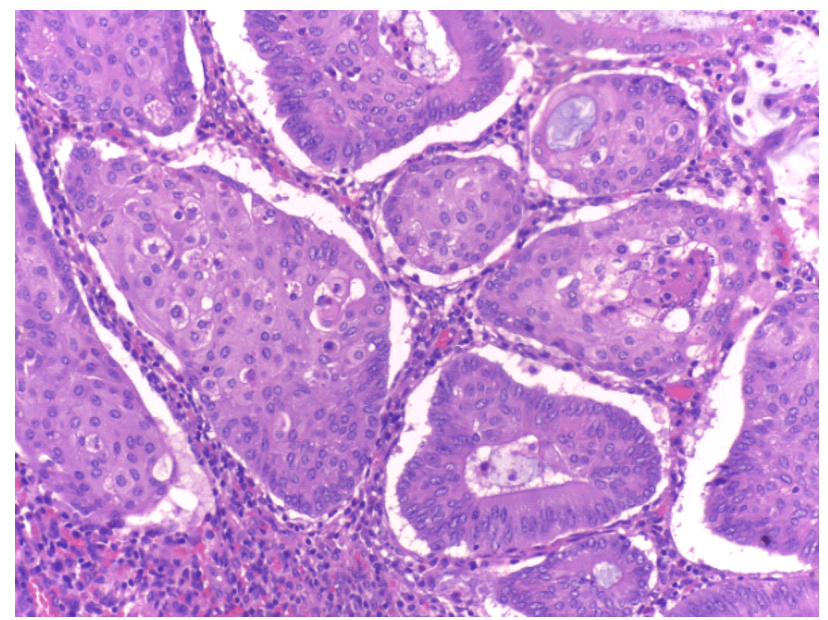

Figure 5 - Squamous differentiation involving adenomatous glands. Note the koilocytic-like changes of some of the squamous cells. HE staining, $\times 200$.

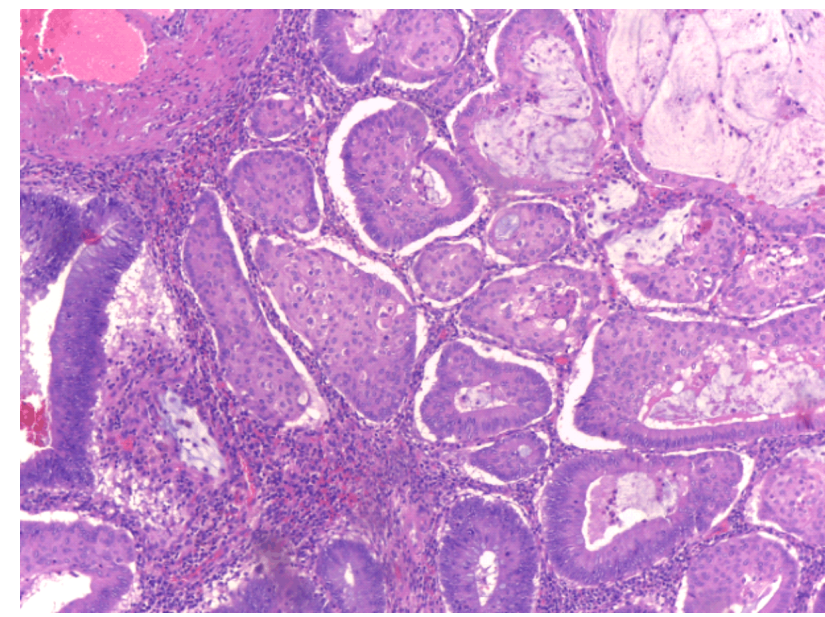

Figure 6 - Multiple foci of squamous metaplasia (morules) in a colonic adenoma with low-grade dysplasia. $\mathrm{HE}$ staining, $\times 200$.

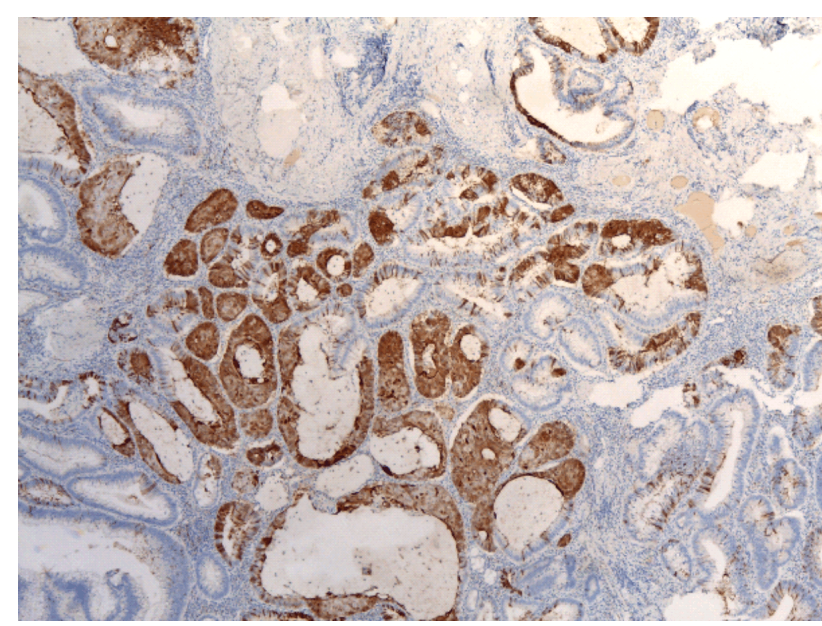

Figure 8 - Immunoexpression of p16 in the areas of squamous metaplasia. IHC staining, DAB chromogen, $\times 100$. IHC: Immunohistochemical; DAB: 3,3'-Diaminobenzidine.

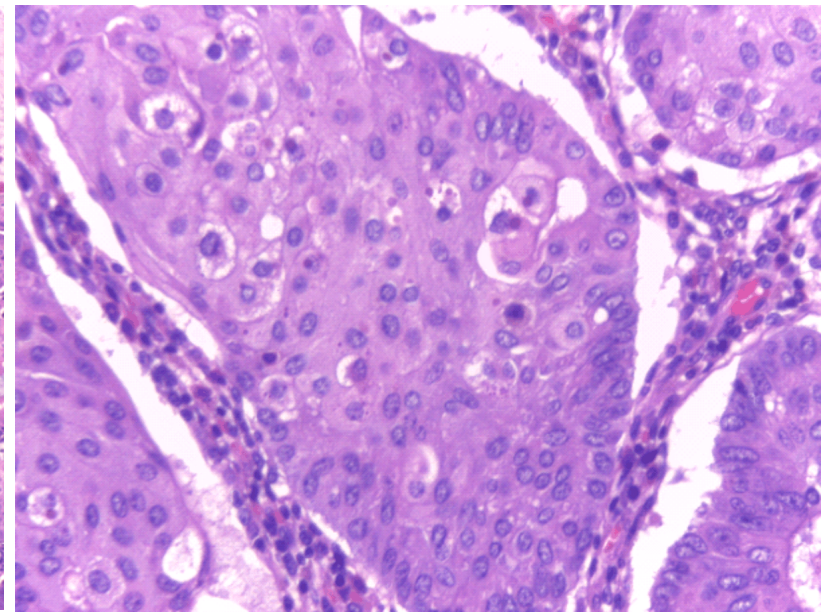

Figure 7 - Koilocyte-like cells, apoptotic bodies and dyskeratocytes in a focus of squamous metaplasia of a colonic adenoma. HE staining, $\times 400$.

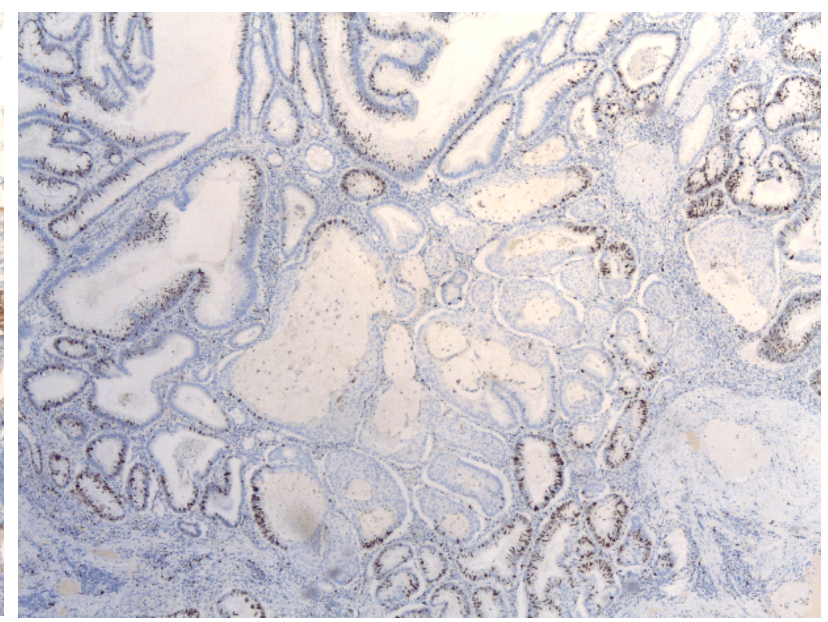

Figure 9 - Absence of Ki67 immunoexpression in the areas of squamous metaplasia. IHC staining, DAB chromogen, $\times 100$. IHC: Immunohistochemical; DAB: 3,3'-Diaminobenzidine. 


\section{Discussions}

The presence of squamous metaplasia within a colorectal polyp is a rare occurrence, with a reported incidence of approximately $0.44 \%$. The predominance of the male gender is confirmed by the current case report, although our patient is slightly younger than the average reported age (54 versus 61 years). Location wise, the sigmoid polyp further supports the findings of Bansal et al. (six out of 20 squamous metaplasias were found in this part of the colon). Histologically, similar to our case, the squamous cells were comprised mostly in tubulovillous components of the adenomas (14 of the 20 cases). Even though the squamous areas seemed to have cellular elements that suggest dysplasia on HE examination, those areas were not mitotically active, as the Ki67 expression showed. Thus, they were considered areas of true metaplasia and not dysplasia [1].

This shift in cellular identity is prompted by environmental stimuli, microorganisms or inflammation and regulated through the action of transcription factors involved in the maintenance of cellular identity and plasticity. The cells adapt to the stress generated by the abnormal stimulus through metamorphosis. It remains unknown whether or not the process is reversible, in the absence of the stimulus. On the other hand, if the predisposing factors linger, metaplasia will progress to low-grade dysplasia, culminating in high-grade dysplasia and malignancy [18].

Squamous metaplasia involves the transition to a multi-layered structure that is thought to have a higher resistance to injurious elements in comparison to normal mucosa. The gene reprogramming can target either progenitor or differentiated cells that outlive mature epithelial cells and replace them after injury. Taking into account the fact that this adaptation occurs as a response to environmental stress, the newly formed squamous epithelium can be surrounded by areas of inflammation, fibrosis and necrosis [18].

The origin of these cells in the current setting could not yet be established. Possible hypotheses are the existence of heterotopic squamous cells nests in the colonic mucosa, metaplastic processes of the glandular epithelial cells or squamous conversion of uncommitted cells from the basal layer. Mechanical irritation and chronic inflammation were suggested as predisposing factors for the emergence of this phenomenon. Crissman stated that persistent stimulation of the reserve cell population leads to the conversion of multipotent cells into the squamous phenotype $[1-3,19,20]$.

The significance of this type of metaplasia in the tubulovillous adenoma with low-grade dysplasia could be that of a premalignant lesion [1]. This hypothesis is partially supported by the IHC findings. P16 is a tumor suppressor gene with function in cell cycle regulation [13-17]. A study performed by Atef et al. (2016) showed that $\mathrm{p} 16$ expression was higher in colorectal adenoma than in colorectal carcinoma ( $72 \%$ versus $22.5 \%$ ), which has supported the statement that gene inactivation or loss plays a crucial part in the carcinogenesis process [21]. However, in the analysis performed by Al-Ahwal et al. (2016), immunoexpression of the gene was slightly higher in colorectal carcinomas, compared to adenomas and normal mucosa, suggesting that the absence of p16 is a sign of the benign course of the adenoma and a key factor in monitoring the progression towards malignancy [13].

\section{a Conclusions}

We present a case of a large tubulovillous adenoma located in the sigmoid. The particularity of this report consists in the presence of multiple foci of p16-positive immunoexpression squamous metaplasia. Despite the fact that the current squamous metaplasia could not be established with certainty as a premalignant lesion, it might play a role.

\section{Conflict of interests}

None to declare. All authors participated in the care of the patient, documentation, writing and corrections of the article.

\section{Ethical standards}

We undersign and certificate that the procedures and the experiments we have done respect the ethical standards in the Helsinki Declaration of 1975, as revised in 2000(5), as well as the national law.

\section{References}

[1] Bansal M, Fenoglio CM, Robboy SJ, King DW. Are metaplasias in colorectal adenomas truly metaplasias? Am J Pathol, 1984, 115(2):253-265. PMID: 6202148 PMCID: PMC1900493

[2] Nirodi NS, Orr KW. Adenomatous polyp of the sigmoid colon with focal squamous metaplasia. J R Coll Surg Edinb, 1986, 31(6):379-381. PMID: 3806459

[3] Chen KT. Colonic adenomatous polyp with focal squamous metaplasia. Hum Pathol, 1981, 12(9):848-849. https://doi.org/ 10.1016/s0046-8177(81)80090-1 PMID: 6895511

[4] Dukes CE. The significance of the unusual in the pathology of intestinal tumours. Ann R Coll Surg Engl, 1949, 4(2):90103. PMID: 18113275 PMCID: PMC2238263

[5] Hayashi I, Katsuda Y, Muto Y, Fujii Y, Morimatsu M. Tubular adenoma with squamous metaplasia of the sigmoid colon: a case report. J Surg Oncol, 1984, 26(2):130-134. https://doi. org/10.1002/jso.2930260211 PMID: 6738058

[6] Kontozoglou T. Squamous metaplasia in colonic adenomata: report of two cases. J Surg Oncol, 1985, 29(1):31-34. https:// doi.org/10.1002/jso.2930290110 PMID: 3990307

[7] Williams GT, Blackshaw AJ, Morson BC. Squamous carcinoma of the colorectum and its genesis. J Pathol, 1979, 129(3): 139-147. https://doi.org/10.1002/path.1711290306 PMID: 529012

[8] Forouhar F. Neoplastic colonic polyp with extensive squamous metaplasia. Case report. Tumori, 1984, 70(1):99-103. PMID: 6710610

[9] Almagro UA, Pintar K, Zellmer RB. Squamous metaplasia in colorectal polyps. Cancer, 1984, 53(12):2679-2682. https:// doi.org/10.1002/1097-0142(19840615)53:12<2679::aid-cncr 2820531219>3.0.co;2-6 PMID: 6722726

[10] Chen YC, Tsai HL, Lin CH, Huang CJ, Wang JY. Adenosquamous carcinoma of the colon. Genomic Med Biomark Health Sci, 2012, 4(3):103-106. https://doi.org/10.1016/j.gm bhs.2012.10.004

[11] Assarzadegan N, Solano FJ. Squamous metaplasia in colorectal polyps. Pathol Lab Med Open J, 2015, 1(1):1-2. https://doi.org/10.17140/PLMOJ-1-101

[12] Ştefănescu D, Streba C, Cârţână ET, Săftoiu A, Gruionu G, Gruionu LG. Computer aided diagnosis for confocal laser endomicroscopy in advanced colorectal adenocarcinoma. PLoS One, 2016, 11(5):e0154863. https://doi.org/10.1371/ journal.pone.0154863 PMID: 27144985 PMCID: PMC4856267 
[13] Al-Ahwal M, Gomaa W, Emam E, Qari Y, Buhmeida A Radwi S, Al-Maghrabi B, Al-Qahtani M, Al-Maghrabi J. p16 protein is upregulated in a stepwise fashion in colorectal adenoma and colorectal carcinoma. Saudi J Gastroenterol, 2016, 22(6):435-440. https://doi.org/10.4103/1319-3767.19 5560 PMID: 27976639 PMCID: PMC5184744

[14] Esteller M, González S, Risques RA, Marcuello E, Mangues R, Germà JR, Herman JG, Capellà G, Peinado MA. K-ras and p16 aberrations confer poor prognosis in human colorectal cancer. J Clin Oncol, 2001, 19(2):299-304. https://doi.org/ 10.1200/JCO.2001.19.2.299 PMID: 11208819

[15] Romagosa C, Simonetti S, López-Vicente L, Mazo A Lleonart ME, Castellvi J, Ramon y Cajal S. p16 $16^{\text {Ink4a }}$ overexpression in cancer: a tumor suppressor gene associated with senescence and high-grade tumors. Oncogene, 2011 30(18):2087-2097. https://doi.org/10.1038/onc.2010.614 PMID: 21297668

[16] Lee MH, Choi BY, Cho YY, Lee SY, Huang Z, Kundu JK, Kim MO Kim DJ, Bode AM, Surh YJ, Dong Z. Tumor suppressor p16 $16^{1 \mathrm{NK} 4 a}$ inhibits cancer cell growth by downregulating eEF1A2 through a direct interaction. J Cell Sci, 2013, 126(Pt 8):1744-1752. https://doi.org/10.1242/jcs.113613 PMID: 23444377 PMCID: PMC3678409
[17] Pritchard CC, Grady WM. Colorectal cancer molecular biology moves into clinical practice. Gut, 2011, 60(1):116-129. https://doi.org/10.1136/gut.2009.206250 PMID: 20921207 PMCID: PMC3006043

[18] Giroux V, Rustgi AK. Metaplasia: tissue injury adaptation and a precursor to the dysplasia-cancer sequence. Nat Rev Cancer, 2017, 17(10):594-604. https://doi.org/10.1038/nrc.2017.68 PMID: 28860646 PMCID: PMC5998678

[19] Hickey WF, Corson JM. Squamous cell carcinoma arising in a duplication of the colon: case report and literature review of squamous cell carcinoma of the colon and of malignancy complicating colonic duplication. Cancer, 1981, 47(3):602-609. https://doi.org/10.1002/1097-0142(19810201)47:3<602::aidcncr2820470330>3.0.co;2-8 PMID: 7226009

[20] Crissman JD. Adenosquamous and squamous cell carcinoma of the colon. Am J Surg Pathol, 1978, 2(1):47-54. https://doi. org/10.1097/00000478-197803000-00006 PMID: 637188

[21] Atef A, Bedeer A. Expression of $\alpha$-methyl-coenzyme A racemase and $p 16$ in colorectal adenoma and adenocarcinoma. Egypt $J$ Pathol, 2016, 36(1):54-60. https://doi.org/10.1097/01.XEJ.00 00484374.45600 .32

\section{Corresponding author}

Lucian Negreanu, MD, PhD, II nepartment of Internal Medicine - Gastroenterology, Bucharest Emergency University Hospital, Carol Davila University of Medicine and Pharmacy, 169 Splaiul Independenţei, Sector 5, 050098 Bucharest, Romania; Phone +4021-601 24 79, e-mail: lucian.negreanu@umfcd.ro 